\title{
Escrever é reescrever: desenvolvendo competências em leitura e escrita no contexto da clínica fonoaudiológica
}

\section{Writing is Rewriting: Developing Reading and Writing Competences in the Context of Speech Therapy}

Rita Signor*

Universidade Federal de Santa Catarina

Florianópolis - Santa Catarina / Brasil

RESUMO: O objetivo deste trabalho é apresentar um recorte de uma pesquisa qualitativa, longitudinal e de cunho sócio-histórico. A finalidade da pesquisa foi o desenvolvimento de uma proposta terapêutica embasada na teoria de gêneros do discurso de Bakhtin. Para a efetivação da proposta, desenvolveu-se um estudo de caso de atendimento terapêutico grupal. O grupo foi composto por cinco adolescentes que apresentavam queixas de dificuldades de leitura e escrita. A proposta com os gêneros partiu da produção escrita de uma peça de teatro, baseada em um romance lido em terapia, da publicação da peça em site e de sua encenação. Apresenta-se neste artigo parte da interlocução com apenas um dos sujeitos do grupo, o sujeito $\mathrm{D}$, em processo de (re)escrita de texto em um dos gêneros abordados: o gênero peça de teatro. Os dados foram analisados à luz do dialogismo bakhtiniano.

PALAVRAS-CHAVE: Terapia fonoaudiológica; gêneros do discurso; linguagem escrita.

ABSTRACT: In this paper we are presenting a part of a qualitative and sociohistorical research, in which we propose a therapy based on Bakthin's theory about speech genres. Our objective was to analyze the contribution of this theory to clinical speech therapy field. We have developed a therapeutic treatment in a group formed by subjects who had complaints about their reading and writing skills. We have selected the following genres in our work: novel, play, synopsis and publicity poster. We have prioritized the genre play because the other genres were used as a part of an activity whose objective was to write a play, that was based on

\footnotetext{
* ritasignor@gmail.com. Doutoranda em Linguística pela Universidade Federal de Santa Catarina e fonoaudióloga.
} 
the adaptation of a novel read during the therapy, to publish it in a website and to stage it. Here we will present just the interlocution with one of the subjects of the group, the subject $\mathrm{D}$, during the process of (re)writing the play. All data was analyzed according to the bakhtinian dialogism.

KEYWORDS: Speech therapy; speech genres; written language.

\section{Introdução}

A questão da aprendizagem da linguagem escrita no Brasil está mais vinculada à noção de fracasso do que de sucesso. Tal fato pode ser constatado por meio de indicadores internacionais ${ }^{1}$ e nacionais de desempenho em leitura, onde os brasileiros figuram sempre entre os últimos colocados. Segundo dados do INAF/2009 (Indicador Nacional de Alfabetismo Funcional), exame realizado desde 2001 , apenas $25 \%$ da população encontra-se plenamente alfabetizada, demostrando que o sistema de ensino brasileiro funciona de forma bastante precária e encontra-se muito aquém de oferecer uma educação de qualidade para a população.

Essa situação, sentida sobretudo por estudantes oriundos de segmentos sociais desfavorecidos, vem sendo justificada por professores e terapeutas como uma problemática constitutiva dos aprendizes. Em outros termos, o aluno que não atinge o padrão esperado pela escola passa a ser concebido, muitas vezes, como portador de distúrbios ou de dificuldades na área da linguagem escrita. Discute-se a problemática em termos de considerações acerca do que faltou para que o sujeito alcançasse as metas impostas; mas não se pensa no que faltou à escola para que cumprisse a sua função de ensinar. $\mathrm{O}$ fonoaudiólogo, ao aderir à queixa da escola, deve estar bem fundamentado para que não incorra em equívocos ao diagnosticar, sob o risco de afastar ainda mais o sujeito dos processos de apropriação da leitura e da escrita.

Acredito que a grande maioria dos problemas decorrentes do insucesso na aprendizagem da leitura e da escrita reflete uma problemática social. A escola tradicional, orientada por um modelo autônomo de letramento (KLEIMAN, 2008), desconsidera os interesses de seus sujeitos e se mostra inflexível ao apresentar um ensino em contextos nada significativos. Apagam-se os usos em torno da linguagem e o aluno diante de uma posição de autoritarismo entra

\footnotetext{
${ }^{1}$ Conforme o PISA/2009 (Program for International Student Assessment), exame internacional que avalia as competências em leitura (entre outras) de estudantes de vários países, o Brasil figurou na 53a colocação dentre 65 países participantes.
} 
em um círculo de relações desfavoráveis ao desenvolvimento do letramento e, em virtude disso, pouco aprende. Ou seja, o trabalho pedagógico voltado eminentemente para aspectos metalinguísticos tende a afastar os sujeitos dos usos sociais da linguagem, desenvolvendo, em grande medida, sentimentos de rejeição frente à língua escrita. Segundo Ana Paula Berberian, Cristiane C. Mori-de Angelis e Giselle Massi:

Os clínicos da linguagem têm obrigação de denunciar tal realidade e de não compactuar com ela, substituindo um olhar simplista e homogeneizante por uma conduta politicamente comprometida com a transformação social. Para isso, é preciso se libertar das amarras de métodos clínicos pautados pela doença e pela norma e aderir a uma clínica verdadeiramente terapêutica, na qual o sujeito e sua história individual, e ao mesmo tempo profundamente social, sejam considerados até as últimas consequências. (BERBERIAN; MORI-DE ANGELIS; MASSI, 2006, p. 30).

Considerando a enorme demanda pelos serviços da clínica fonoaudiológica por sujeitos com supostas dificuldades de leitura e de escrita, penso que uma prática embasada na teoria de gêneros do discurso de Bakhtin possa ser um recurso terapêutico de grande valia. Preconizo que, através das relações de sentido que a teoria bakhtiniana propõe, seja possível reverter o quadro de instabilidades decorrentes de relações sofríveis com a modalidade escrita da linguagem.

Assim, por meio da inserção dos sujeitos em práticas sociais de leitura e escrita, aproximam-se os sujeitos da linguagem, que, engajados em contextos significativos de uso da língua, desenvolvem competências necessárias às demandas sociais em uma sociedade letrada. Acredito que é lendo, escrevendo, revisando, reescrevendo, ${ }^{2}$ publicando o material escrito, que o aluno/paciente gradativamente se apropria da linguagem escrita.

O objetivo deste trabalho é apresentar um recorte de um processo terapêutico que foi realizado com adolescentes com queixas de dificuldades na área da linguagem escrita. Tal processo, embasado na teoria de gêneros do discurso de Bakhtin, fez parte de um estudo longitudinal, qualitativo, de cunho sócio-histórico, que teve por intuito analisar a contribuição da teoria em questão para o campo do atendimento clínico na área da leitura e escrita.

${ }^{2}$ Neste artigo dou especial ênfase ao processo de reescrita de texto. 


\section{Método}

Para dar conta do objetivo delineado, desenvolvi e avaliei uma proposta de pesquisa e terapêutica, que configurei como um estudo de caso de um atendimento fonoaudiológico em grupo. O grupo foi composto por cinco sujeitos, entre 11 e 13 anos, que foram encaminhados por suas escolas por apresentarem, segundo parecer dos professores, dificuldades relacionadas à linguagem escrita (compreensão e produção escrita). $\mathrm{O}$ atendimento clínico foi embasado na perspectiva enunciativo-discursiva de linguagem e a concepção bakhtiniana de gêneros do discurso fundamentou teoricamente a atuação fonoaudiológica.

Assim, durante o processo, selecionei um grupo de gêneros do discurso para nortear a ação terapêutica: romance, peça de teatro, cartaz de divulgação $\mathrm{e}$ sinopse. Dentre esses, priorizou-se a peça de teatro, sendo os demais gêneros decorrentes e necessários ao enfoque centrado em uma proposta de elaboração, publicação e encenação de uma peça. Para a escrita da peça de teatro, partiu-se da reenunciação/adaptação de um romance lido em terapia. ${ }^{3}$ Para a publicação da peça em site e sua encenação, os sujeitos produziram os gêneros sinopse e cartaz de divulgação. Nesse contexto, os participantes da pesquisa se inseriram em uma série de práticas sociais de leitura e escrita visando à concretização da ação fonoaudiológica voltada para a apropriação, pelos sujeitos, das práticas de leitura e produção de textos mediados por esses gêneros.

Os dados para a pesquisa foram gerados no período de novembro de 2008 a janeiro de 2010. As sessōes terapêuticas foram documentadas com auxílio de um gravador de áudio e de um diário de campo. Outros instrumentos de pesquisa foram: questionários respondidos por escrito pelos pais, entrevistas com os pais, relatórios dos professores e prontuários médicos. As transcrições das falas seguiram a convenção da escrita. $\mathrm{O}$ atendimento foi realizado em uma sala do ambulatório de leitura e escrita de um Hospital Infantil. As sessões foram realizadas em grupo, com alguns atendimentos individuais. ${ }^{4}$

\footnotetext{
${ }^{3}$ Nesse romance, dois irmãos adolescentes acham na casa para a qual acabaram de se mudar um objeto/esponja (grool) que traz azar a quem o possuir ou a quem estiver próximo a ele. Durante toda a trama, os irmãos (Kat e Daniel) tentam se livrar do grool, mas ele parece imortal.

${ }^{4}$ As sessōes de terapia em grupo foram realizadas uma vez por semana e tiveram por volta de três horas de duração. As sessões individuais, por sua vez, tiveram em torno de uma hora e meia de duração.
} 
Importante considerar que para este artigo apresento um dos sujeitos do grupo, o sujeito D, em processo de reescrita de texto - parte de uma peça de teatro (um dos gêneros selecionados para a terapia).

Para dar tratamento analítico-qualitativo aos dados gerados nos episódios dialógicos, utilizou-se a teoria enunciativo-discursiva explicitada por Bakhtin (análise dialógica do discurso-ADD). Uma abordagem epistemológica sóciohistórica que se oriente pelas concepçôes bakhtinianas tem, como categoria central, o dialogismo, uma vez que busca atingir os sentidos estabelecidos e promovidos nas situaçōes interacionais.

Este trabalho foi aprovado pelo Comitê de Ética da UFSC, sob processo número 132/09. Foram assinados os Termos de Consentimento Livre e Esclarecido. ${ }^{5}$ Como o intuito para este trabalho é apresentar parte da interlocução com um dos sujeitos do grupo, a seguir realizo a apresentação do caso.

\section{Apresentação do caso}

D convive com os pais e uma irmã, que tinha, à época deste estudo, 2 anos de idade. A família vive na cidade de Florianópolis. D havia sido aprovado, quando do início do processo terapêutico, para o $5^{\circ}$ ano do ensino fundamental, nunca tendo sido reprovado. Tinha, na ocasiáo, 11 anos de idade.

Sobre a relação de $\mathrm{D}$ com a escola, seus pais disseram, em resposta a um questionário escrito, que o filho gostava de ir para o colégio e que também tinha uma boa relação com os professores e colegas. Demonstraram satisfação com a escola: "é um colégio muito bom". ${ }^{6}$ A mãe escreveu, em resposta à questão "como você vê o seu filho", que o vê como uma criança muito inteligente "apessar dele escrever muitas coisa erradas. Só na escrita, um pouco e por causa que ele não fez um jardim para se aperfeiçoar e por falta de leitura". Ressaltou que o problema começou a se manifestar no $2^{\circ}$ ano "só que foi diminuindo conforme o tempo, na quarta série ele só troca as letras, mas ele é um menino que entende sempre as explicações, mas as vezes ele adora conversar muito em sala de aula”.

Com relação ao temperamento do filho, os pais assim escreveram:

\footnotetext{
5 A pesquisa (mestrado em Linguística) foi orientada pela Professora Dra. Rosângela Hammes Rodrigues.

${ }^{6}$ Os trechos reproduzem a escrita dos pais. O questionário escrito foi um recurso utilizado para a análise das condiçōes de letramento da família.
} 
Ele é um menino muito bom, só que é um pouco teimoso, faz as coisas muito devagar, um pouco preguiçoso, adora participar de todas as coisa na escola, futebol, fazer trabalho escolar, etc. A relação em casa é normal, fora de casa ele adora faz amizade que para ele é muito fazil, uma das coisa que ele adora amizade nova.

Com relação à escolarização no contexto familiar, a mãe concluiu o ensino fundamental e o pai finalizou o ensino médio; ela é do lar e ele representante comercial. A mãe disse gostar de ler poesias e tudo o que lhe chama a atenção (lê apenas de vez em quando), já o pai prefere ler diariamente as principais notícias veiculadas pela internet.

D não toma nenhum tipo de medicação. Possui uma rotina adequada para um menino da sua idade, adora assistir televisão, acordar tarde e brincar, mas não gosta, conforme a mãe, de dormir cedo e também não gosta de ler e escrever.

A seguir, o discurso da escola:

D iniciou seus estudos em nossa escola no ano de 2004.

Atualmente está cursando a quarta série do ensino fundamental. $\mathrm{O}$ mesmo foi aprovado [para a quinta série] em Conselho de Classe, pois apresenta grandes dificuldades na linguagem escrita.

É um aluno muito alegre, educado e esforçado. Tem um ótimo relacionamento com a professora e com seus amigos.

$\mathrm{O}$ aluno apresenta dificuldades na escrita e na leitura. Na maioria das vezes ao escrever troca as letras, exemplo: $f$ por $v, v$ por $f, b$ por $p, m$ por $n$. Apresenta esta dificuldade desde os primeiros anos de alfabetização. Entendemos que o mesmo precisa de ajuda profissional, pois apenas os esforços da professora e também do próprio aluno para resolver esse problema não estão sendo suficientes. Quanto a sua leitura é silábica e tem dificuldades de interpretação.

Em relação a disciplina de matemática o aluno tem se desenvolvido muito bem. Consegue resolver com sucesso as atividades.

$\mathrm{Na}$ avaliação fonoaudiológica do sujeito, durante a leitura realizada com o conto "O sábio e o criminoso", de Rosane Pamplona, percebi que D apresentou discreta diminuição na fluência do material lido e uma compreensão parcial do texto; foi quando sugeri a ele que lesse o conto novamente. Com a segunda leitura, ampliou a macroestrutura que havia sido anteriormente construída; no entanto, não respondeu às perguntas inferenciais. 
A análise realizada em torno das produçōes de textos (sugeridas durante o processo de avaliação) revelou que o sujeito era capaz de expressar sua intenção discursiva por meio de sequências linguísticas dotadas de sentido. Necessitava, no entanto, intensificar suas ações na/com a linguagem (como qualquer aprendiz) para que, por meio da ação com e sobre textos, no âmbito de práticas sociais de leitura e escrita, pudesse ir ampliando seus conhecimentos acerca do funcionamento da escrita nos diferentes gêneros discursivos.

Com relação aos aspectos formais, percebi que $\mathrm{D}$ parecia (em seus textos) dar pouca atenção ao uso da pontuação. Apresentava, ainda, algumas substituições entre grafemas surdos e sonoros, como em voi/foi e lempro/embro. Conforme Raquel Salek Fiad (2006), essas trocas são comuns na fase de apropriação da escrita, pois representam fonemas com o mesmo ponto articulatório e que se diferenciam apenas pelo traço de sonoridade. $\mathrm{D}$ também apresentava algumas ocorrências de hipossegmentação como em lanacidade/lá na cidade, que podem estar relacionadas ao fato de o adolescente representar, na escrita, unidades rítmico-entoacionais da fala. Além disso, D escreveu disi, felis, doses, o que se justifica pelo fato da escrita (em língua portuguesa) se valer de diferentes grafemas para representar um mesmo fonema, gerando conflitos que ocorrem naturalmente na trajetória de aquisição da escrita. Reitero que tais hipóteses (reflexôes sobre o funcionamento da língua) fazem parte do percurso de apropriação da modalidade escrita da língua e são superadas no próprio exercício da linguagem. Assim, a prática da linguagem, em contextos significativos, é suficiente para que o sujeito amplie sua competência discursiva, avançando, inclusive, em conhecimentos de aspectos textuais e formais da língua escrita.

A aceitação para terapia deu-se, desse modo, em virtude da queixa apresentada pela escola que, refletindo no discurso da família, fez com que D impusesse à sua autoimagem a noção de "mau leitor" e "mau escritor", revelando à terapeuta, em avaliação, que não gostava de ler e de escrever, pois não sabia ler e escrever muito bem; afirmando, inclusive, que escrevia "tudo errado". A conduta terapêutica teve como objetivo reverter essa condição.

A seguir, apresento excertos da interlocução relativa à décima segunda sessão de terapia. Esta sessão foi realizada individualmente para que fosse percebida, de forma mais aprofundada, a apreensão dos conhecimentos adquiridos nas sessões passadas. Cabe ressaltar que as sessōes anteriores foram destinadas à leitura do romance que seria adaptado para uma peça de teatro/ roteiro escrito, bem como a sessōes de leitura e análise de peças de teatro e de 
outras estratégias de apropriação do gênero peça. Para esta sessão havia sido solicitado a cada sujeito do grupo de terapia que tentasse em casa realizar a adaptação de um dos capítulos do livro, para que, em sessão, seguíssemos com o processo de revisão e reescritura da produção realizada. A seguir, o processo realizado com $\mathrm{D}$.

\section{Resultados}

Vejamos, abaixo, a primeira versão do texto de D (realizada em casa), referente à reenunciação do capítulo 2 da obra em questão:

(1) Daniel - Eu não tive que achá-lo (rido). Ele não se perdeu.

(2) Kat - O que você quer dizer?

(3) Daniel - Prendi valente no porão (contou orgulhoso) enquanto você estava na

(4) varanda corri para a porta lateral e me escondi debaixo da pia.

(5) Kat - você é mesmo um ratão!

(6) Kat (escuta um tarulho) - que barulho é esse?

(7) Daniel - Ah não é um rato de verdade (ele gritou) - Kat por favor. Pare...

(8) Eu... não... aguento.

(9) Kat - Vai entregar os pontos (perguntei)

(10) Kat - sim ele disse sem fôlego (rindo)

(11) Kat - tudo bem eu respondi generosa - Vou deixar você levantar agora

(12) Daniel - Obrigado ele agradeceu. - Ei o que valente está fazendo ali.

(13) Kat - esqueça não vou cair nessa outra vez (declarei)

(14) Kat - (que estranho valente nunca rosna) - eu pensei

(15) Kat - O que você pegou ai garoto (perguntei para ele)

(16) Daniel - O que é Kat? (Daniel perguntou)

(17) Kat - acho que não é nada de epecial. acho que é só uma velha esponja

(18) (respondi)

(19) Kat - valente (eu critei) - menino feio

(20) Kat - Daniel olhe isso aqui (exclamei) - Nossa não acredito nisso! 
Procedi à leitura do texto de $\mathrm{D}$ e antes de passarmos para o processo de reelaboração, eu disse a ele todos os pontos fortes de sua produção escrita, como, por exemplo, o fato de ele realizar as indicaçóes dos nomes dos personagens de forma adequada (no canto esquerdo da folha) e também de ele ter conseguido, na maioria das vezes, segmentar as falas e as microrrubricas/ indicações de cena (açôes dos personagens e tom de suas falas). Afirmei ainda que este era um trabalho de reflexão bastante complexo e que ele já havia desenvolvido grande parte do percurso de apropriação do gênero peça de teatro. Disse, por outro lado, que havia ainda alguns aspectos que precisavam ser aprimorados em relação à produção de peças, e que tais aspectos seriam estudados comigo (terapeuta/pesquisadora-T) e os colegas. Após a leitura, intentei conduzi-lo a uma reflexão sobre a sua escrita. Comecei por perguntar se ele havia lido sua produção:

$$
\text { [01 - } 12 \text { mar. 2009] }
$$

T: Diz uma coisa pra mim... Você, depois de escrever... ou mesmo durante... quando você estava escrevendo... Você leu, você viu, foi vendo como tava ficando?

D: Não (diz baixinho e com um sorrisinho meio sem graça).

T: Você pediu pra sua mãe ou pra alguém ler o seu trabalho pra ver se tinha ficado bem claro, se dava pra entender direitinho?

D: Minha mãe tá só com a G [irmã] que não para de mexer nas coisas.

\section{$[\ldots]$}

T: Tá... seu texto tá bom... mas temos que ver umas coisinhas pra ficar melhor ainda... Lê aqui (3) essa fala do Daniel... Que que tá escrito nessa parte que não faz parte do jeito de escrita do roteiro?

D: (lê e não encontra o "problema”).

T: Daniel contou orgulhoso?

D: É. Tá aqui no livro, ele contou orgulhoso.

T: Mas ele contou?

D: Olha aqui (mostra o livro para T) ele contou sim.

T: Lembra... Você está escrevendo uma peça de teatro. As coisas vão acontecendo na hora que o público tá vendo a peça. No roteiro Daniel CONTA orgulhoso.

D: Esqueci. Tem que pôr conta...

T: Isso mesmo. Por que que no roteiro tem que pôr os verbos nas indicações no tempo presente? 
D: Porque... Porque tá ali, não é igual no livro, é na hora, igual na peça que a gente viu, ${ }^{7}$ as coisas ali na mesma hora...

Cabe ressaltar que sempre antes de solicitar qualquer atividade de escrita, oriento meus pacientes/sujeitos a realizarem uma revisão, o que implica a (re)leitura de suas produçôes. Percebo que tal sugestão é assumida pelos sujeitos de forma gradativa. Eles já possuem uma atitude de não leitura, não retomada, não reflexão, não revisão, provavelmente construída no processo da escolaridade. Isso já pode ser percebido na sessão de avaliação fonoaudiológica, pois produzem textos e entregam imediatamente, indicando que não são leitores de seus próprios escritos.

A escola, em sua grande maioria, não incentiva o diálogo do autor com suas produçōes. A esse respeito, Fiad (2006) afirma que um escritor proficiente tende a realizar "diversas escritas" até chegar àquela considerada desejável, a versão definitiva do autor, uma vez que "até se dar por satisfeito com seu texto, o escritor o refaz, modifica-o, deixando em seus manuscritos os rastros de seu percurso" (FIAD, 2006, p.71). A autora salienta que apesar de algumas escolas já estarem incentivando o processo de reescritura, como ocorrem em alguns manuais didáticos: faça um rascunho e depois reescreva o texto, o que ainda predomina é a tradição de um ensino de escrita centrado em conteúdos gramaticais. Dessa forma, nós, terapeutas, temos de reconduzir essa situação levando o aprendiz a uma atitude de escritor eficiente, ou seja, aquele que se póe como leitor de seu escrito e analisa os efeitos de sentido de sua produção, assumindo uma posição de distanciamento diante do que escreve.

Um bom texto/enunciado é aquele que permite a um interlocutor presumido construir um eixo de sentido por meio do processo de leitura. Assim, pensando em constituir um escritor eficiente em situação de terapia, perguntei a $\mathrm{D}$ se ele havia lido seu texto ou pedido a alguém que o lesse. A propósito, o fato da pergunta ter causado certo "acanhamento" em D já leva a crer que ele

${ }^{7}$ Como uma das estratégias para a apropriação do gênero peça de teatro, levei os integrantes do grupo para assistir a uma peça (no teatro da UBRO) em Florianópolis. Outra estratégia igualmente importante foi a de resgatar (com os sujeitos) a situação de interação do autor com o interlocutor, que se distingue nos gêneros romance e peça de teatro. No romance a interação distante pressupóe a marcação dos acontecimentos no tempo pretérito. Na peça de teatro, por sua vez, a interação concomitante com o público faz com que a marcação dos verbos nas indicações de cena esteja no tempo presente. 
considerou o fato de não ter lido/relido como um possível "deslize". Importante comentar que o tom de minha fala não apresentou qualquer tipo de censura em razão de ele não ter lido; ao contrário, apenas questionei com o intuito de tentar reconstituir o processo de produção do texto em casa e de também ir provocando em $\mathrm{D}$ a necessidade de reler.

Em seguida, ainda me colocando como interlocutora da produção de D, fui proporcionando momentos para que ele pensasse em seu escrito. Em um primeiro instante, pedi a ele que observasse um trecho particular de sua produção (3) e tentasse visualizar o que em sua escrita não era específico da composição textual de uma peça teatral (indicação de cena com os tempos verbais no pretérito). Tal atitude objetivou fomentar a construção de uma posição de escritor ainda mais proficiente, ou seja, de alguém que se envolve de tal forma com seu trabalho de escrita que a ele recorre diversas vezes até chegar ao resultado final. D relê o trecho (3) e não percebe que eu estava tentando chamar sua atenção para a indicação da cena. Eu trouxe, dessa maneira, a situação de interação autor/leitor para que ele refletisse um pouco mais sobre a escrita do gênero peça de teatro. Isto significava observar que há aspectos específicos da linguagem para atender os interactantes de dada esfera particular de atividade humana.

Após ter percebido que não havia colocado a indicação adequada conforme demanda o gênero em estudo, manifestou: "Esqueci. Tem que pôr conta...". Fiz, então, uma pergunta para analisar se realmente ele havia compreendido o motivo de a indicação ter de ser realizada daquela forma: "por que que no roteiro ${ }^{8}$ tem que pôr os verbos nas indicaçoes no tempo presente?". Percebi que ele havia entendido a razão pela qual as indicaçóes ocorriam no presente, tanto que trouxe para a interlocução fatos já vivenciados em interações passadas, como a peça assistida: "é na hora, igual na peça que a gente viu"; e a comparação das especificidades da peça e do romance: "não é igual no livro", ou seja, ele retomou o dito recente e ainda o complementou com outras informações (movimento de complementaridade). A minha ação junto a D teve como objetivo favorecer o desenvolvimento da aprendizagem do gênero, e, para isso, mediei todo o processo por meio de perguntas provocadoras.

${ }^{8}$ O gênero em questão é nomeado peça de teatro ou roteiro de teatro. Contudo, roteiro está mais ligado ao texto escrito. Peça de teatro é um termo mais abrangente, uma vez que representa, além do texto escrito (o roteiro), a encenação. 
Tais perguntas são importantes em um ambiente terapêutico em que se supõem determinados rompimentos e provocações para novos sentidos. $\mathrm{O}$ fato de $\mathrm{D}$ e os demais sujeitos desta pesquisa terem ficado meses apenas "memorizando" classes de palavras nas atividades desenvolvidas no contexto de suas escolas, ${ }^{9}$ atividades essas descontextualizadas de uso da língua, colocaram-me em uma posição de "resgate" desses sujeitos/pacientes. A quebra da pseudolinguagem ${ }^{10}$ estabelecida nas práticas escolares foi possível pelo uso da língua em situações significativas, mediadas por questões geradoras de processos reflexivos. João Wanderley Geraldi (1997), quando fala da escola, diz que a relação de mediação e aprendizagem deve ser permeada por produção de linguagem e não por mera repetição de conteúdos a serem transmitidos ou desprovidos de qualquer tipo de significação. Tomo as considerações do autor e as trago para minha prática clínica.

Dando continuidade à reflexão conjunta, observei que $\mathrm{D}$ operou no processo de reenunciação considerando apenas as falas dos personagens do romance; a parte narrada ele simplesmente omitiu. Desse modo, tentei fazer com que percebesse que tal atitude criou problemas no seu texto, na medida em que os "saltos" comprometeram a formação do sentido, tornando seu escrito menos efetivo. A mediação proporcionada efetivou-se no sentido de demonstrar como a leitura, objetivando a revisão do texto, possivelmente teria conduzido à minimização desses problemas. Mas tornar um sujeito/paciente um escritor competente é um processo que demanda algum tempo. Algo que, sob nosso ponto de vista, deveria ser incentivado pela escola já desde as primeiras produções textuais de seus alunos.

O episódio abaixo exemplifica um pouco do que quero enfatizar:

[02 - 12 mar. 2009]

T: [...] O que é esse "pare, não aguento", o que que a Kat não aguenta? [linha 7-8]

D: Não lembro direito.

T: Dá uma olhada no texto.

D: (procura no texto) É que o Daniel tá fazendo cócegas nela.

\footnotetext{
${ }^{9}$ Esta informação está baseada na observação dos cadernos de Língua Portuguesa dos sujeitos.

${ }^{10}$ Termo utilizado por Terzi (2002) ao definir as práticas de linguagem estabelecidas em sala de aula.
} 
T: Então D, tem que explicar senão como o leitor do seu texto vai saber? Como é que seus colegas na hora de estudar o roteiro pra apresentar vão ficar? Perdidos... Tem que explicar tudo, se a Kat diz pra Daniel parar é porque ele tá fazendo alguma coisa. Tem que dizer o que ele tá fazendo pra então dizer que Kat pediu pra ele parar, senão seus colegas poderão se perder... E eles precisam fazer uma boa leitura do texto, para poder fazer uma boa apresentação... pro público entender tudo também. O texto não pode ter esses pulos. Toma, lê e vê se você percebe isso que eu tô falando...

Observei que durante a leitura de sua produção, ou seja, no papel de leitor de seu escrito, D percebeu alguns problemas no estabelecimento do sentido, tanto que por algumas vezes levantava a sobrancelha numa atitude de, digamos assim, compreensão do que havia sido dito anteriormente. Foi possível constatar que o modo como se dava a mediação não apenas favorecia a formação de um escritor competente, mas também a formação de um leitor competente, pois o fato de se criar, na interação, a necessidade da análise/revisão do texto provocava uma leitura real, ou seja, não leitura-decodificação, mas leitura-significação.

Penso ser importante tocar nesse aspecto já que a minha prática clínica e dados de pesquisa, como os de Terzi (2002), sugerem que as crianças submetidas a processos educacionais inadequados tendem a acreditar que a pura decodificação implica uma atividade real de leitura. A autora observou que seus sujeitos, quando liam um texto e por ventura pulavam uma linha, não percebiam e continuavam lendo, demonstrando a despreocupação com a atribuição de sentidos ao ato de ler. Do mesmo modo, durante a "leitura", produziam palavras com trocas de fonemas como todia ao invés de podia e não estranhavam o fato de estarem produzindo palavras desconhecidas da língua, "provavelmente, por terem sido expostas, desde o início da alfabetização, a palavras cujo significado não conheciam. Isto as faria, crer, agora, serem os sons que produziam também palavras desconhecidas" (TERZI, 2002, p. 61). A autora considera que o conceito de linguagem construído na vivência em muitas escolas não conduz os sujeitos a perceberem o funcionamento da linguagem em situações de uso efetivo da língua. Concordando com a autora e tentando ressignificar, na prática clínica, as atividades de leitura e escrita vivenciadas na escola, é que tive por objetivo levar D a ser leitor e escritor eficaz de seu próprio texto.

Importante observar, no episódio dialógico acima, que o outro é parte integrante dos processos discursivos. Lembrar o sujeito de que seus interlocutores imediatos e distantes poderiam ter a interação com o seu escrito 
comprometida foi um fator fundamental, que tornou a prática de escrita interativa e, portanto, significativa. A especificidade do gênero constituiu parte integrante de todo esse processo de desenvolvimento do conhecimento da leitura e escrita. $\mathrm{O}$ efeito que a perspectiva de um trabalho centrado no gênero traz é proporcionar a ampliação das capacidades discursivas, pois além de o sujeito estar se desenvolvendo na linguagem, está concomitantemente se apropriando do gênero. $\mathrm{O}$ avanço é inegável se considerarmos que os gêneros do discurso são categorias concretas de uso da linguagem, possibilitando que se trabalhe de forma integrada com todas as suas dimensões. Assim, as questões sintáticas, ortográficas, semânticas, se focadas em nível discursivo, ganham sentido na apropriação da linguagem escrita.

Ilustro essa consideração com um episódio dialógico estabelecido na interação, em que, em conjunto com $\mathrm{D}$, percebemos que o lugar da vírgula poderia mudar totalmente o sentido do dito, ou seja, que a forma se constituía em uma estratégia fundamental do ato de dizer:

[03 - 12 mar. 2009]

T: Ah, aqui nessa... Lê pra mim... [em 7]

D: (lê) Ah... não é um rato de verdade...

T: $\mathrm{D}$, tô em dúvida... não é um rato de verdade, é isso?

D: [...] Acho que não era... não, não era, era o Daniel com roupa de rato... fantasia acho...

T: Mas não é Daniel que tá falando, que tá gritando?

D: Ai é... péra (vai no livro). É... Foi antes... foi antes que Daniel pôs roupa de rato...

T: Mas é rato ou não é rato?

D: É rato, T. Ele tá falando que é um rato de verdade.

T: Mas ó o que você disse que não era um rato de verdade... você leu que não é um rato de verdade e o carinha tá dizendo que é rato... Pensa comigo, olha aqui... o que tá escrito aqui?

D: Não é... um rato... não é um rato de verdade...

T: Mas é!

$[\ldots]$

T: O que que eu preciso pôr aqui pra indicar... pra dizer que é um rato... que Daniel tá querendo dizer que o barulho na cozinha é de um rato de verdade. 
D: Eu botei o "não" tem que tirar o "não", daí fica que é um rato.

T: Ótima saída, você pode fazer assim, mas se você quiser deixar o espanto do Daniel, é só pôr a vírgula aqui (escreve no papel)... entende... Ah não, é um rato de verdade!... só o lugar da vírgula diz se é rato... se não é rato.

D: Nem precisa tirar o não...

T: É. Tem que ver na hora de escrever... tu vê... uma vírgula pode mudar todo o sentido do negócio... "Ah, não é um rato de verdade" é bem diferente de dizer "ah não, é um rato de verdade!".

Ao trabalharmos no nível do discurso, estamos interessados em mobilizar a linguagem escrita em conjunto com nossos sujeitos/pacientes e, com isso, produzir sentidos. O terapeuta, como interlocutor/leitor dos escritos de seus sujeitos/pacientes, pode explorar a composição dos textos produzidos e buscar, com o sujeito, escolhas dentre as diversas possibilidades de uso da modalidade escrita da língua. Em outros termos, o terapeuta poderá estar no entremeio do texto produzido (produto) e seu produtor (autor). Chamar a atenção para a colocação da vírgula, como mostra o episódio acima, e para a significação desse fato, ou seja, que a pontuação pode alterar completamente o sentido do dito, tende a operar uma modificação no texto e no sujeito que por ele se transforma. É refletindo sobre os sentidos atrelados ao objeto que o sujeito vai agindo sobre ele, modificando-o, adequando-o à situação enunciativa e à sua intenção de dizer. $\mathrm{O}$ fato de refletirmos com D ("É rato ou não é rato?") e com ele buscar a solução, proporcionou uma situação de confronto no uso da linguagem. O movimento de leitura da obra para a produção da peça (escrita), de leitura da peça para a escrita, e de volta à leitura da obra, fecha um círculo ao qual subjaz o discurso (o que dizer) e as formas desse discurso (como dizer o que se tem a dizer).

Uma vez criadas as condições para a ocorrência das atividades interativas, seja por meio da produção dos textos, seja por meio da leitura de textos, é no interior dessas atividades que, conforme Geraldi (1997), a análise linguística se dá. $\mathrm{O}$ autor diz que as reflexões que remetem ao interior do texto podem servir para prover conhecimento sobre a língua(gem) e também podem proporcionar o domínio de recursos expressivos. "Toda reflexão deve estar no horizonte: o confronto entre diferentes formas de expressão, incorporadas àquelas já dominadas pelos alunos, levam à produção e ao movimento de produção de variedade padrão contemporânea” (GERALDI, 1997, p. 193). Desse modo, penso que os próprios textos dos alunos/pacientes servem para orientar as 
reflexões possíveis que desses textos resultam. Ou seja, os possíveis "problemas" de um texto podem ser o trampolim para se discutir encaminhamentos de recursos expressivos mais adequados à comunicação discursiva. Dessa forma, perceber junto com $\mathrm{D}$ que a posição da vírgula poderia indicar, ou não, a existência de um rato remete a uma operação discursiva engendrada numa "proposta de compreensão" (GERALDI, 1997).

Fui observando outras hipóteses que D vinha fazendo acerca da escrita do roteiro:

[04- 12 mar. 2009]

T: Só mais uma coisa, aqui [em 14] no "eu pensei". Como é que a gente mostra um pensamento em cena? ${ }^{\text {?1 }}$

D: Pensamento?

T: No livro, claro, todo mundo pensa o tempo todo... É só escrever o pensamento e as pessoas ficam lendo os pensamentos dos personagens.

D: Então é só tirar.

T: Ah... Mas aí a gente vai perder muita coisa interessante... interessante e importante pra história.

D: É...

T: Vamos ver... não tem pensamento em cena... tá... o que que tem em cena? $\mathrm{Na}$ hora de escrever o roteiro o que que você tá colocando?

D: Boto fala...

T: E o que mais?

$\mathrm{D}: \mathrm{O}$ que as pessoas faz...

T: O que falam e o que fazem... então, temos que transformar o pensamento em fala ou em ação...

D: Mas ela [Kat] vai falar sozinha?

T: D, tem problema em falar sozinho?

D: É meio esquisito.

T: D, não é a vida real. É uma representação da vida real. Não é você, o $M,{ }^{12} \mathrm{oL}$ que vão tá lá em cima. São os personagens que vocês vão representar. Não é a J que vai ta lá no palco falando, quem vai falar éa Kat... A J vai tá representando a

11 "Kat - (Que estranho, Valente nunca rosna) - eu pensei."

${ }^{12} \mathrm{~L}, \mathrm{M}, \mathrm{J}$ e ED indicam as iniciais dos demais integrantes do grupo terapêutico. 
fala que é da Kat... A J pode achar estranho falar sozinha, mas a Kat pode não ver problema nenhum nisso, entende? Na hora de escrever tem que pensar nisso.

D: Não sei... não sei botar o pensamento...

T: Se bem que aqui... o Daniel tá na cena... fica como se ela tivesse falando com ele... mas vamos pensar no pensamento porque toda hora aparece pensamento no livro... Vamos pensar se o Daniel não tivesse... Dá pra simular pensamento... A gente podia pôr ela como se ela tivesse pensando... pensando alto... falando baixinho... Tipo: "Que estranho, Valente nunca rosna..." falando sozinha mesmo... o roteiro não é escrito pra ser falado? O público não tem o recurso da leitura. O povo tá assistindo. São as falas e as ações mesmo.

D: Aí não põe parênteses.

T: É. Mas não era ação mesmo, porque você tinha posto entre parênteses?

D: Porque era pensamento aí achei que não dava pra ser fala, que tinha que ser ação...

T: Tem que ler e ver o que você pode fazer... Esse pensamento dá para virar uma fala? Esse pensamento vira uma ação, dá certo? Pensa sempre no público. No que você quer provocar nesse público. O que for melhor pra eles entenderem. O que fica mais bonito... mais emocionante... ou no nosso caso, o que fica mais apavorante!

D: E se não der?

T: Não der o quê?

D: Nem fala nem ação.

T: Ah... difícil... mas se não der, faz que nem você falou antes, tira. Você tem que pensar e ver o que é possível fazer... Dá pra inventar também... mudar. Não precisa ser igual o livro. Imagina.

É possível perceber que hipóteses vão surgindo à medida que se estabelece a interação com o objeto e com o outro (terapeuta). Como expressar o pensamento de um personagem no palco? $\mathrm{D}$ havia colocado o pensamento da personagem entre parênteses como se fosse uma ação (não verbal) - sua hipótese naquele momento. Quando, no entanto, questionei a respeito de como resolver o suposto "problema" (o de expressar o pensamento em cena), ele simplesmente disse: “então é só tirar”, sem refletir sobre o que tal supressão poderia significar (atitude estabelecida e enraizada no contexto escolar?). Como a mediação em clínica pressupõe levar o sujeito a um processo de reflexão, fui realizando perguntas provocadoras a fim de fazer com que D se atentasse para a importância dos pensamentos para a trama e para o fato de que eles poderiam sim ser expressos no palco. 
Nessa caminhada para a resolução do problema foram geradas outras dúvidas, como a pergunta realizada por D: "Mas ela [a personagem] vai falar sozinha?" A pergunta de $\mathrm{D}$ denota que ele estava se reportando mais à realidade cotidiana do que à encenação propriamente dita. $\mathrm{O}$ fato de pensar em alguém falando sozinho, por mais que esse acontecimento ocorra cotidianamente, gerou certo estranhamento para $\mathrm{D}$. Talvez uma maior vivência no sentido de assistir espetáculos teatrais favorecesse a compreensão de que os personagens muitas vezes "dialogam consigo mesmos" durante a encenação. Faltou a D o distanciamento necessário para perceber que ele estava reelaborando um ato cotidiano de forma artística.

Nesse ponto é importante compreender como Bakhtin (2008) entende a atividade estética. Para o autor, o fazer estético discretiza elementos da realidade (da vida) e os transpõe para um plano fora dessa realidade. O escritor (no caso da arte literária) dá acabamento que se materializa em uma forma composicional, em um material linguístico. Ao transpor para o plano artístico os elementos do cotidiano e da cognição, o escritor permite o trabalho estético, quer dizer, a modelagem desses elementos em outro plano, em outra unidade de sentidos e valores; é o que, segundo Bakhtin, constitui a especificidade do estético. Diz o autor que a atividade estética só é possível em decorrência do distanciamento do autor-criador, que no seu agir-fazer, olha essa atividade (a arte) de fora.

No processo de mediação fui provocando situaçōes para que $\mathrm{D}$ pudesse ir gradativamente percebendo que na atividade de produção escrita da peça os personagens "falavam por si", numa tentativa de provocar o distanciamento necessário à atividade de criação. Assim, em relação ao pensamento da personagem, foram mencionados exemplos de possibilidades que poderiam ser pertinentes para o objetivo de D em sua ação de escrita: "dá pra simular pensamento; a gente podia pôr ela como se ela tivesse pensando... pensando alto... falando baixinho...". Também, levando o sujeito a pensar em seu interlocutor - "pensa sempre no público... no que você quer provocar nesse público... no que for melhor para eles entenderem... no que fica mais emocionante..." -, pretendi, por meio das condiçôes de produção de linguagem, trazer o sentido responsável pela aprendizagem.

Penso que ser escritor, produzir textos, significa agir sobre o outro. Pressupõe, então, uma relação de parceria em que um sujeito que sente, que pensa, portanto, que diz, materializa o seu querer-dizer em um enunciado dirigido a outro sujeito, que igualmente pensa, sente, diz. Para isso, é necessário que os sujeitos se apropriem de uma série de capacidades linguístico-discursivas 
e cognitivas. Ser leitor, compreender textos, é também apropriar-se dessas capacidades e, para além de saber relacionar grafemas e fonemas, é interagir e engajar-se em um processo de construção de sentidos, "mergulhando" no querer-dizer do outro. Assim, trazer o outro para a terapia de leitura e escrita é proporcionar efeitos transformadores nos sujeitos que se desenvolvem nas/pelas práticas de linguagem.

Durante o processo de releitura de seu texto, $\mathrm{D}$, em conjunto comigo, observou que escreveu algumas palavras inexistentes na língua, como rido e tarulho, ou seja, a mediação conduziu à reflexão, que fez com que o aprendiz percebesse algumas inadequações ortográficas.

Abaixo, a segunda versão produzida em terapia:

DANIEL - Eu não tive que achá-lo (rindo). Ele não se perdeu.

KAT - O que você quer dizer?

DANIEL - Prendi valente no porão (conta orgulhoso). Enquanto você estava na varanda corri para a porta lateral e me escondi debaixo da pia.

KAT - Você é mesmo um ratão! (escuta um barulho). Que barulho é esse?

DANIEL - Ah não, é um rato de verdade (fala gritando). Kat, cuidado!

KAT (sobe em cima da cadeira). Socorro!

DANIEL (morrendo de rir) - te enganei de novo!

KAT (pula em Daniel e fais cosegas nele) - Prepare-se para morrer de rir!

DANIEL - Kat por favor. Pare... Eu... não agüento.

KAT - Vai entregar os pontos? Tudo bem vou deixar você levantar agora.

DANIEL - obrigado. Ei, o que valente está fazendo ali?

KAT- Esqueça, não vou cair nessa outra vez.

[Valente fica mexendo embaixo da pia e rosnando]

KAT - Que estranho valente nunca rosna. Que você pegou aí garoto?

DANIEL - O que é kat?

KAT - acho que não é nada de especial. Acho que é só uma velha esponja. Olha como é pequena, redonda e maron-claro.

KAT (tenta tirar a esponja de valente e ele rosna). - Valente, menino feio! (diz gritando).

KAT (segura a esponja perto do rosto) - Daniel olhe isso aqui. Nossa, não acredito nisso! 
Cabe ressaltar que a produção escrita acima passou ainda por processo de revisão em grupo antes de ser publicada, juntamente com os demais capítulos, no site Recanto das Letras. Após o referido processo de refacção textual, D seguiu em processo terapêutico, recebendo alta quinze meses depois.

\section{Considerações finais}

É importante, ao término deste trabalho, refletirmos sobre o sujeito bakhtiniano, o sujeito relacional; aquele que se apropria da linguagem na relação com o outro (FARACO, 2009). E que a depender da qualidade dessas interações, o sujeito pode avançar em relação aos seus conhecimentos sobre a língua, ou rejeitá-la, e com isso desenvolver "sintomas" na área da linguagem.

A teoria de gêneros do discurso de Bakhtin pressupõe conceber a linguagem como um fenômeno sociointeracional, ideológico e, portanto, dialógico. Ao buscar essa perspectiva teórica para o campo da atuação fonoaudiológica com sujeitos encaminhados para atendimento clínico - em virtude de portarem supostas dificuldades de leitura e escrita, segundo "diagnóstico" das escolas frequentadas por eles -, eu pretendia, por meio de contextos significativos de uso da língua, nos quais se observa o funcionamento da noção de gêneros, fazer com que esses sujeitos se aproximassem da linguagem escrita e interagissem por meio dela, desconstruindo, assim, o estigma da dificuldade.

Desse modo, travou-se um embate sociodialógico nos processos de aprendizagem da escrita em situação de terapia fonoaudiológica. A descrição e análise deste estudo conduzem a perceber que, ao assumir a interlocução como espaço de produção de linguagem escrita, é possível observar os sujeitos produzindo textos, lendo, relendo, reescrevendo suas produções, ou seja, desenvolvendo conhecimentos/estratégias de escritores e leitores competentes, como pudemos verificar pelos excertos apresentados com o sujeito D.

Assim, ao se apropriar dos gêneros do discurso focados nas práticas desenvolvidas, consequentemente desenvolvem-se competências necessárias a essa apropriação, como as de revisor e reescritor das próprias produções e alheias (como no caso das abordagens grupais). Ademais, no trabalho visando à apropriação do gênero, o sujeito, em contextos de sentido, opera na construção do objeto escrito ao mesmo tempo em que desenvolve posturas afetivas frente à linguagem eà sua própria condição de leitor e autor. 


\section{Referências}

BAKHTIN, M. Problemas da poética de Dostoiévski. Rio de Janeiro: Forense Universitária, 2008.

BAKHTIN, M. Estética da criação verbal. São Paulo: Martins Fontes, 2003.

BARBOSA, J. P. Do professor suposto pelos PCNs ao professor real de língua portuguesa: são os $\mathrm{PCN}$ praticáveis? In: ROJO, R. A prática de linguagem em sala de aula: praticando os PCNs. São Paulo: Mercado de Letras, 2008. p. 149181.

BERBERIAN, A. P.; MORI-DE ANGELIS, C.; MASSI, G. Letramento: referenciais em educação e saúde. São Paulo: Plexus, 2006.

BERTHOLD, M. História mundial do teatro. São Paulo: Perspectiva, 2008.

FARACO, C. A. Linguagem e diálogo: as idéias linguísticas do Círculo de Bakhtin. São Paulo: Parábola, 2009.

FIAD, R. S. (Re)escrevendo: o papel da escola. In: ABAURRE, M. B. M.; FIAD, R. S.; MAYRINK-SABISON, M. L. Cenas de aquisição da escrita: o sujeito e o trabalho com o texto. Campinas: Mercado de Letras, 2006. p. 71-77.

GERALDI, J. W. Portos de passagem. São Paulo: Martins Fontes, 1997.

KLEIMAN, A. Os significados do letramento: uma nova perspectiva sobre a prática social da escrita. Campinas: Mercado de Letras, 2008.

PEIXOTO, F. O que é teatro. São Paulo: Brasiliense, 1981.

RODRIGUES, R. H. Os gêneros do discurso na perspectiva dialógica da linguagem. In: MEURER, J. L.; BONINI, A.; MOTTA-ROTH, D. (Org.). Gêneros: teorias, métodos e debates. São Paulo: Parábola, 2005. p. 152-183. TERZI, S. A construção da leitura. São Paulo: Pontes, 2002.

Recebido em 30/08/2012. Aprovado em 19/10/2012. 